\title{
E-CRM dilemmas in developing markets: The case of a tourism company in Serbia
}

\author{
Alexandros Kapoulas ${ }^{1 *}$ and Dražen Ratković ${ }^{2}$
}

Received: 30/10/2013 Accepted: 24/04/2014

\footnotetext{
${ }^{1}$ City College International Faculty of the University of Sheffield, 3 Leontos Sofou Str., 54626, Thessaloniki, Greece, Tel.: +30 2310 536544, 528450 (ext.115), Email: akapoulas@city.academic.gr

${ }^{2}$ GR liaison at CEI office in NIS Gazprom-neft, Email: ratkovicdrazen@yahoo.com

* Corresponding author
}

\begin{abstract}
This paper explores introduction of e-Customer Relationship Management in the tourism services industry in Serbia. By using a case study methodology, this paper reflects the attitudes of top management in Serbia's biggest tourist agency regarding e-CRM implementation, where five top managers were interviewed, starting from general director, down to regional directors. Findings indicate that managers of this particular company are divided into two groups, based mostly on their age, but also based on their educational background. In this study, key informant interviews were conducted with the General Director, Commercial Director, Marketing Director, Product and Sales Manager and Turkish and Alpine Department Manager. They were identified as the key decision makers in the process of adoption of e-CRM at the "Alpha" tour operator. Same number of interviewees was used by Kothari et al. (2007) in their study regarding the process of adoption of an e-Procurement technology in a hotel company. As a result, most managers agreed that online customization of the arrangements, as an investment, would create only a niche market; and by niche market they mean a small market segment that is not worth spending money on.
\end{abstract}

(C) 2015 International University College. All rights reserved

Keywords: e-Customer Relationship Management, tourism services, Serbia, case study

Citation: Kapoulas, A. and Ratković, D. (2015). E-CRM dilemmas in developing markets: The case of a tourism company in Serbia. European Journal of Tourism Research 9, pp. 24-40

\section{Introduction}

Throughout the $20^{\text {th }}$ century, the dominant marketing paradigm was that of transactional marketing (Harker and Egan, 2006), and within that perspective, marketing was regarded as a managerial problem, and its focus was only on how to sell organizational products (Hultman and Shaw, 2003). Since in transactional marketing there was a high level of information asymmetry in the entire marketing process, and the level of interaction with customers, along with personalization, was on a very low level, the new paradigm had to evolve into something completely new; something that would take care of the problems created by the 
transactional marketing paradigm (Tapan, 2006).

Therefore, Customer Relationship Marketing (CRM), has become a key for differentiation among many participants in the tourism market, and it has successfully enhanced its predecessor, transactional marketing (Howe, 2011). Afterwards, relationships are given a central place in the development of marketing models used in a services context (Grönroos, 2007), but researchers are constantly echoing new thoughts in the tourism industry, which is why an in-depth conceptual exploration is still very much lacking in this area (Xiang and Petrick, 2008).

Tourism workers in developing markets are aware that strong competition and global access to information, products and services, will result in clients expecting continuous communication with the company and superior compliance with their demands (Amila, 2010). Therefore, any company that is part of "estory", must strive to offer high quality and personalized products, services and many additional benefits that will attract new customers, and retain existing customers (Amila, 2010).

That is why this paper aims to examine the implementation of e-CRM in the tourism industry in a developing economy, the Serbian market, where it is a "new" concept, since emerging markets are facing many difficulties in developing e-business activities (James, 2009).

In order to further analyse where the country stands in terms of CRM implementation and acceptance, an analysis of "Alpha", a leading company in Serbian tourism will provide a good test-bed of the current situation.

The remainder of the paper is organized as follows: First, we begin with a brief literature review on CRM, the evolution of e-CRM and its applications in tourism and more particularly in tourism in Serbia. Then, we describe our research methodology, followed by the findings presentation. Finally, we conclude with a discussion of the research and its implications and limitations.

\section{E-CRM}

Over the last two decades, the travel and tourism industry has experienced remarkable changes in its organizational structure due to the increased use of the Internet in business processes (Taga, Gaspari and Vukaj, 2011). The advent of the Internet, along with increasing globalization and growing competition have brought fundamental changes in the way information about travel and tourism products are distributed and delivered (Taga, Gaspari and Vukaj, 2011).

E-CRM is a new phenomenon that involves mainly the Internet, web technology and other interactive technologies to initiate and facilitate relationships between suppliers and customers (Fux et al., 2007; Pan and Lee, 2003). According to Blery and Michalakopoulos (2006) organizations that adopt e-CRM, by reducing the cost of contacting customers, can put more resources into dealing with customer enquiries, which can lead to increased profitability.

Successful e-CRM efforts should be based on a strategic plan, up to date technology and the quality of employees' work (Morphitou, 2009) with a deeper understanding of the difficulty of incorporating culture, process, people, and technology within and across organizational contexts (Finnegan and Currie, 2010).

For an organization some important benefits exist when using an e-CRM approach such as quick service/response time, two-way interactive service relationships, and the ability to supply services to customers from anywhere at any time (Pan and Lee, 2003). In addition, e$\mathrm{CRM}$, increases consumers mobility amongst products and suppliers (Sigala, 2006), customer satisfaction and service, online sales, website patronage, loyalty, retention and profitability (Ab Hamid, 2005; Adebanjo, 2003; Feinberg and Kadam, 2002; Jayachandran et al., 2005; Kotorov, 2002; Letaifa and Perrien, 2007; Teng et al., 2007).

Lee-Kelley et al., (2003, p. 241) are referring to "e-CRM as marketing activities, tools and techniques delivered over the Internet (using technologies such as web sites, email data capture, warehousing, and mining) with a specific aim to locate, build and improve long- 
term customer relationships to enhance their individual potential. Al-Momani and Noor, (2009) point out that use of e-CRM within businesses has increased dramatically over the last few years, and will continue to do so in the future. This is true since e-CRM can develop companies regardless of their sizes and industries. However, small and medium sized companies implement simplistic forms of eCRM (Harrigan et al., 2011), which offer oneto-one relationships to customers and create an enormous amount of value by allowing them to collect, organize and disseminate a wealth of customer information (Pan and Lee, 2003). However, in order for e-CRM to be successful it must be integrated into an overall enterprisewide customer-centric strategy rather than being treated as a separate and distinct approach (Peppard, 2000).

Anyhow, Buttle (2004) indicates that a strategic alternative of e-CRM does not exist for enterprises; as such, they should develop a relentless approach towards creating customer centricity because, through this, they will achieve current, future and lifetime profitability by creating customers for life, and interviews with managers proved this theory right.

\section{E-CRM in Tourism Industry}

Prior to the computerization of the industry, the role of a travel agent was to advise clients on destinations and to act as an intermediary in the complicated process of arranging travel bookings (Mamaghani, 2009). Later on, however, the development of information and communication technologies transformed tourism into a just-in-time information-based and -intense industry (Karanasios and Burges, 2008).

The lasting effects of the new technologies have improved information accessibility, raised the levels of competition, and transformed both consumers and businesses travel markets around the globe (Mamaghani, 2009). As such, travel agents are now preoccupied with providing highly competitive services and focusing on gaining customer loyalty given the plethora of options available to travellers (Heng-Hsiang and Chou-Kang, 2006). The internet has offered tour-operators a chance to represent themselves in an e-market place, to offer direct bookings, to reduce advertising costs; it enabled global distribution 24 hours a day and greater interactivity with customers globally, not just locally as in the past (Buhalis, 1999).

The entire travel industry has been faced with increasing threats from the dynamic pricing that is offered through online direct sales channels (Amila, 2010). Consumers now have a chance to find lower-priced travel online; many of them are using the same method in order to search for all their travel needs (e.g., car rental, hotel, airline tickets, attractions and events) through a one stop shopping approach. The fact is that information technology had literally cut out the "proverbial middleman" in this sector (Mamaghani, 2009), since by selling directly to consumers online travel agents offer prices and value added services unavailable through traditional travel agents (Khosrow-Pour, 2006).

Customization, as added value, had become of extreme importance due to the fact that the number of competitors is constantly increasing because of globalization, and at the same time customer's lifestyles and perceptions about risk involvement in tourism product purchasing are constantly changing due to increased IT usage Buhalis (1999).

That is why today's travel retailers require increased knowledge not only about product and service offerings, but also about the customer. Knowledge has played a key role in recent years, not only in selling, but also in cementing a customer relationship that will mean more business in years to come (Hale, 2006). The relationships that CRM is trying to create between the agency and the customer are difficult to achieve via e-CRM, since e-CRM is a technology based business relationship (computer to computer, individual to computer, or computer to individual), which facilitates exchanges of information or value without in person contact (Kennedy, 2006).

However, in order for individuals or businesses to begin using e-CRM in the first place, e-trust must be developed first (Matopoulos et al., 2007). Research has shown that traditional CRM has rapidly evolved into e-CRM, but that up to 50 percent of implementations yield 
unsatisfactory returns due to functional (non)usability and user and management resistance factors (Sampaio and Yong, 2006), and whether or not e-CRM will be accepted by the clients also depends on where they are positioned on the "stone age man" to "gadget boy" continuum (Bonnemaizon, et al. (2007).

Information technology (IT) enabled CRM to become the solution to the problem that travel and tourism industries are facing due to new technology implementation, and the problem is finding a unique way to attract and maintain customers. According to Thomas (2002), travellers follow predictable patterns in their planning, which is why travel marketers need to consider their visibility and presence in places where travellers look to shop for destinationsboth online and offline.

Thus, in order to attract a larger and more diverse audience, tourism operators have faced the necessity to invest in, and leverage, IT in order to promote their programs, since e-CRM can apply sophisticated web features because of the advantages associated with program size (e.g., superior financial resources, more technological expertise, and meticulous management strategies) (Hu et al., 2005). Accordingly, more and more firms in the hospitality sector invest significant amounts of money to take advantage of the integration and business expansion offered by e-CRM systems (Racherla and $\mathrm{Hu}, 2008$ ).

Companies are investing since implementing eCRM will be able to provide them with low cost leadership, product differentiation and will enable them to concentrate on niche markets, while the importance of niche markets will differ depending on the context Fletcher et al. (1995).

Recent studies in Greece, show that tourism firms have low adoption rates of e-CRM 2.0 (Sigala, 2011), while hotels did not seem to apply many of the relationship marketing strategies due to difficulties in staff training (Samanta, 2009), although tourism firms have understood the importance of using e-CRM to implement their marketing strategies.

However, implementing e-CRM may not be a straightforward procedure within Serbian tourism enterprises, regardless of the fact that tourism products are the most frequently searched for on the web, they are far behind the banking and insurance sector in terms of implementation (Gospic and Bogojevic, 2010).

\section{E-CRM in the Tourism Industry in Serbia}

Little has been written about e-CRM implementation in developing economies such as Serbian, and even less in the tourism sector, which is why companies that do try to introduce CRM, and especially e-CRM, do so based on US models which are, arguably, not very well suited to such economies (Holden, 2001). For example, there are critical differences between North American society and developing economies, particularly in the Balkan Peninsula, in terms of institutional context, social and cultural norms, legislation, economic environment, corporate governance, political environment, and traditional education systems (Holden, 2001).

Due to the fact that only few researches are examining e-CRM implementation in general, examples from banking sector (Kapoulas et al., 2002) had to be used, where in his study Kapoulas et al. (2002) considered the preliminary emergence of theoretical patterns in relation to how electronic media networks and electronic relationship marketing can impact upon the facilitating of improved customer relationship management by financial services institutions.

The fact that qualitative research of e-CRM implementation in tourism industry is lacking could make this research extremely important for future e-CRM implementation in tourism services sector, since it will, to some extent, create comparative CRM practices understanding.

Serbia is a country with a comparably low internet penetration rate of only $12 \%$; but yet Serbia is also a country that is experiencing growth in its online population (James et al, 2009). The most current data for Serbia indicates that about $47 \%$ of households own a computer (56\% in urban and $34 \%$ in rural) with nearly $45 \%$ never having used a computer (Republic Statistical Office, 2010). Currently, fast internet, or ADSL, covers a paltry $5 \%$ of 
the country (Gospic and Bogojevic, 2010), while almost $30 \%$ of households still use modem enabled dial-up internet (Republic Statistical Office, 2010); this is a burden to the expansion of online purchasing in the country since research of Reinartz et al. (2004) has showed that page download has to be less than 8 seconds, while the entire purchase process should not be longer than 10 minutes in order for a customer to buy the product. Adding to the connection and access problems, $57 \%$ of Serbians have never used the internet, while the overall growth in usage is only $9 \%$ and $2 \%$ in urban and rural areas respectively (Republic Statistical Office, 2010).

Despite these issues, $57 \%$ of internet users in Serbia used the internet to find information, and $35 \%$ of those were directly related to tourism and accommodation but $90 \%$ have never bought online (Republic Statistical Office, 2010). This may be partially explained by the fact that some websites do not offer online purchase options. It has been suggested that some of the key reasons for Serbians avoiding online purchases includes: the lack of online banking legislature, the lack of experience in online purchases completion, unfriendly user websites and interfaces (Gospic and Bogojevic, 2010), connection costs, connection speed, limited credit card availability, lack of secure online payment methods, availability of local content, availability of own-language websites, logistical barriers related to physical product delivery, and outages (Strauss et al., 2006).

However, research by Harris and Davison (1999) indicated that another important fact must be considered when dealing with developing countries, and that factor is culture; since their study of six different Asian markets showed that all developing countries are showing considerable cultural heterogeneity, which then suggests that e-business predictors in emerging markets may differ even in close geographic proximity.

In other words, different cultures have different information needs and search behaviour; also, the items of information sought in a travel guidebook, and the use of information sources by specific cultural groups will differ from items of information sought by another group, and will therefore affect the eventual purchase. It must also be expected from the literature that the differences between cultures will be more heavily emphasized if cultures are divided into the extremes of Western versus Eastern cultures (Osti et al., 2009). It has been suggested that the key reasons that Serbs are avoiding online purchases include: the lack of legislation related to online banking, the lack of experience in online purchases completion, and unfriendly websites and user interfaces (Gospic and Bogojevic, 2010). It has also been suggested that tourism in Serbia lags far behind the banking and insurance sector in CRM implementation (Gospic and Bogojevic, 2010), which leads directly to the overall significance of this research.

Apart from cultural factor, another six important predictors of e-business adoption need to be stressed, and those are English language capabilities, internet infrastructure, computer infrastructure, affordable telephone service, literacy rate and logistical infrastructure (DiGregorio et al., 2005).

Companies in Serbia, including tourist agencies, are being encouraged to introduce new management systems and to apply tools generally recognized and accepted in developed markets (e.g. CRM); however, customers are not "punishing" them if they do not do so, simply because they do not know any better (Milikić et al., 2008). Furthermore, companies that have tried to introduce CRM in the Serbian market have done so based on North American text books, which is the model not very well suited to Serbia, simply because of the "critical differences between North American society in terms of institutional context, social and cultural norms, legislation, economic environment, corporate governance, political environment, tradition and the education system" (Holden, 2001).

Studies in developed countries assume that a set of prescriptive CRM change activities works well in any given context, but such studies are ignoring the broader contextual environment, while it is actually other way around (Desai and Sahu, 2008). The same CRM change strategy that has succeeded in context of developed 
countries may be a sure way to failure in emerging markets (Desai and Sahu, 2008).

In less developed countries, and especially countries from the former Eastern Block, people feel higher levels of collectivism, power distance and uncertainty avoidance, which inhibit "new" adoptions, regardless of the benefits (Zupan and Kase, 2005).

When implementing CRM in Serbia it has been suggested that a series of socio-cultural dimensions have to be taken into account (e.g., power distance, individualism, masculinity, uncertainty avoidance and dynamism) since according to previous studies fundamental cultural differences are existing between AngloAmerican dominated societies and Eastern European countries which are more, based on Russian ideologies (Hofstede, 2001).

A good example of customization of e-CRM for specific market is showed in research of PilavVelic (2010). This research illustrates a five step approach, developed for the Bosnian market, which is very similar to Serbian, and it could easily be implemented by managers in tourism sector as well as in other sectors in the Serbian market.

It can be concluded that CRM implementation in Serbia will be very specific and that an American model of CRM implementation cannot be easily transferred given that Serbian capitalism has only been restored in the last twenty years and only ten years has passed since the beginning of European integration; Serbian companies and consumers are still evolving towards modern market predictability (Adzic and Jevtic, 2010), but since implementing e-CRM will enable for tourism products to be bought without almost any physical effort, and with no time pressure involved Buhalis (1999), Christou \& Kassianidis

Table 1. Suggestions for Implementation of E-CRM for the Serbian Tourism Industry

Step 1: E-CRM concept as business philosophy

Step 2: e-CRM technologies

Step 3: Interaction with clients

Step 4: Data privacy policies

Step 5: Successfulness of e-CRM
Acceptance of client relation management as business orientation

Focus on client

- Acceptance of e-CRM by all employees

- Creation of e-CRM department inside of the company

- Collection and analysis of client data

- E-mail, web pages, weblog analyses, contact centres

- Good software solutions and assessment of their success

- Getting to know your client (demands regarding quality of service, prices, delivery speed and the paying method)

- Communication channels (e-mail, contact centre, web searchers or print media...

- Relationship personalization

- Defined privacy policy

- Introducing clients to the policy

- Trust of the clients during the online purchase

- $\quad$ Frequency of webpage visits

- Participation of online shoppers in overall income

- Percentage of repeated purchases

- Frequency of complaints and reclamations

Responsiveness to the client inquiries

- Client loyalty programs 
(2002); Faulkner et al. (2001) Serbians will eventually adopt this concept.

\section{Methodology}

In this study, we chose the case study methodology (Yin, 2008), since e-CRM in tourism is a new and emerging concept. Scholars assert that case studies can bring rich data to light (Fink and Disterer, 2006; Fruhling and Keng, 2007; Gerring, 2009) and it is well suited for capturing knowledge from practitioners (Bonoma, 1985; Fruhling and Keng, 2007).

To address the research query we have chosen the exploratory case study research design. This study aims to analyse perceptions regarding e-CRM initiatives in the Serbian market. Based on our purpose, we selected a leading company in tourism services sector. In particular, the company "Alpha" is a leading tour operator in Serbia with more than 100 employees and it has been operating for around 20 years. After the case selection, we picked out the experts to be interviewed to gather empirical data (Kapoulas et al., 2002). Managers interviewed were chosen based on their job role within their company, their professional experience and skills and their specialized knowledge in relation to the topic being investigated, and they were asked to reflect upon their attitudes towards ecommerce, about profitability of implementation
The interviews were conducted during the period of May and June 2010. Their duration did not exceed 1 hour, interview was consisted of 10 questions, and those were conducted within working hours of the managers. In order to gain a full picture of the issue, five in depth interviews were arranged with "Alpha" agency's senior management cadre. The interview guide that was designed was sent to the interviewees before conducting the interview, so that they could be prepared and approve any comments. To ensure the quality of the research process with regard to validity, reliability and reflexivity, similar procedures are suggested for the conducting of case studies as for qualitative exploratory research in general (Carson et al., 2005; Flyvbjerg, 2006; Yin, 2008; Moore N. and Stokes P., 2012). A semi-structured interview guide was used and the interviews were audiorecorded to increase accuracy of data collection and transcribed verbatim (Priporas and Poimenidis, 2008; Priporas and Vangelinos, 2008) and translated from Serbian to English for analysis. Regarding the data analysis approach the authors used the constant comparative method of data analysis as it is suggested by Merriam (1998). Comparing the data gathered through the interviews and then comparing the findings with the existing literature. These comparisons led to the construction of categories and subcategories. By determining the efficacy of categories derived from the constant

Table 2. Respondents Profile

\begin{tabular}{|c|c|c|c|c|c|}
\hline Respondent & Gender & Age & $\begin{array}{l}\text { Educational } \\
\text { Background }\end{array}$ & $\begin{array}{l}\text { Current } \\
\text { position }\end{array}$ & $\begin{array}{c}\text { Years of } \\
\text { experience }\end{array}$ \\
\hline M1 & Male & 37 & Bachelor Degree & $\begin{array}{l}\text { Turkish and } \\
\text { Alpine } \\
\text { Department } \\
\text { Manager }\end{array}$ & 12 \\
\hline M2 & Male & 55 & $\begin{array}{l}\text { Bachelor } \\
\text { Degree }\end{array}$ & $\begin{array}{l}\text { General } \\
\text { Director }\end{array}$ & 30 \\
\hline M3 & Male & 30 & PhD & $\begin{array}{l}\text { Marketing } \\
\text { Director }\end{array}$ & 5 \\
\hline M4 & Male & 30 & Master Degree & $\begin{array}{l}\text { Commercial } \\
\text { Director }\end{array}$ & 4 \\
\hline M5 & Female & 44 & $\begin{array}{c}\text { Associate } \\
\text { Degree }\end{array}$ & $\begin{array}{l}\text { Product and } \\
\text { Sales Manager }\end{array}$ & 20 \\
\hline
\end{tabular}

of e-CRM, and finally upon product customization. comparative method of data, the authors checked category formation guidelines against 
Merriam (1998) while constructing the categories for this investigation.

\section{Findings}

Participant profiles

Managers participating in the study were selected based on their position within the company. The majority were males with at least a bachelor degree and considerable working experience. Table 1 provides several insights into the participants.

\section{Attitudes of managers towards e-commerce in general}

Clear difference emerged between managers that graduated during communist era, whilst those who graduated more recently. When asked about their attitudes towards a lack of face to face contact in e-commerce managers' responses were quite contradictory. One group of managers is determined to push towards "complete" electonisation, where face to face contact will no longer present them with any problems:

"It looks to me that worldwide e-commerce is becoming a trend and everything is going towards complete electronisation. Definitely there is significant number of clients who will refuse to transfer to ecommerce, especially since tourism products are very specific; but that will only make e-CRM a bit harder to implement in the tourism industry, since people usually like to get advice from someone before they decide; however, this will disappear when new millennium generations become those who are spending the money" [M3].

"Considering the structure of our clients I don't think that a lack of face to face contact will represent a problem for them, since we have a large group of clients that are 50 years old and above; they have never used a computer before, and they are not going to start now. For the other group I also think it will not be a problem since we will know everything about them, and if they travelled before, through our database, which will tell us where they usually travel, how much money they usually spend, and whether they complain often...our marketing department also considers impressions of our guides... we will be able to have a clear picture about them, without face to face contact" [M4].

This topic, however also has a contradictory perspective:

"My experience is not only from the tourism (sector) but also from banking, and I can say that when in direct contact with the clients, who are still insecure regarding their choice of destination, type of arrangement and etc., nothing can replace face to face contact; just like ATM machines never totally replaced bank branches. That is especially true when talking about tourism since it is the kind of product that always must be additionally explained; specifics must additionally be stated; benefits and risks also. I don't think that it can be done through the internet and people do need to have a live person in front of them" [M2].

When asked about the importance of face to face contact the difference between "old school" and "new school" managers was clear. Younger managers' discussed an segmentation approach where clients, above 50 years old, would not even be targeted through an e-commerce campaign; new generation clients, or those who would accept everything offered to them online, would not perceive a lack of face to face contact as a problem. These statements of "Alpha's" management are in contradiction with the research of Buttle (2004) who indicated that a strategic alternative of e-CRM does not exist for enterprises; as such, they should develop a relentless approach towards creating customer centricity because, through this, they will achieve current, future and lifetime profitability by creating customers for life.

Younger managers of "Alpha" do not perceive CRM introduction in the same way as Buttle (2004), but more as Bonnemaizon et al. (2007), who stated that whether or not people embrace the benefits of e-CRM depends on where they are positioned on the "stone age man" to "gadget boy" continuum. On the other side, "old school" managers tend to claim that face to face contact is a necessity in the tourism 
industry and that an agency branch can never be replaced, which is again supported by the work of Bonnemaizon et al. (2007).

\section{Attitudes of managers towards e-CRM implementation profitability}

In relation to the question of e-CRM implementation profitability, all respondents agreed that it will eventually be profitable, but not at the beginning; and only if implemented correctly. They pointed out that "Alpha", as the market leader, has to implement this, regardless of costs, if they want to stay ahead of the competition:

"It will definitely be profitable eventually, but only if it is done in the proper way. ECRM cannot be good or bad, everything will depend on implementation" [M1].

"In the long term it will bring profit, in the short term no. We will have to direct it at the younger generations. We already have a program for them and subscribers of that program are often revisiting the website. They are internet-focused and open to new markets, and in three years, when they start to work, they will have their own money and will continue to use internet services offered to them. We have to keep up with the changing conditions. We don't actually have a choice here since if we want to keep up with the world, and if we want to remain leaders in the region, we have to be first in everything" [M3].

Here, in fact, they have disagreed with the statement of Davids (1999), who claimed that CRM implementation can face serious difficulties, or even outright failure, if it does not deliver profitable growth and it can even damage existing customer relationships; "Alpha's" managers' are claiming that ecommerce must be implemented at any cost, even if at the expense of existing client relationships.

\section{Attitudes of managers towards customization}

When asked to discuss online customization as a sign of trust towards the agency, since through this clients are buying arrangements "unseen", scepticism was evident in all cases but one, due to the fact that foreign agencies will always offer better prices since they have a bigger market to draw from; however, one of the managers stated:
"We are aiming to have two types of arrangements: package arrangements on the one hand, and on the other hand those in which people will select where and how they want to go, and we will make that possible for them. This will certainly raise their levels of satisfaction". [M3]

When asked about online customized arrangements as a sign of trust for the agency, managers showed a significant lack of understanding, since all but one perceived that it is only a niche market which can easily be taken away by bigger foreign agencies, and that this option is only a waste of money. This statement does not coincide with the view of Buhalis (1999) who stated that customization, as added value, is of extreme importance due to the fact that the number of competitors is constantly increasing due to globalization, and at the same time customer's lifestyles and perceptions about risk involvement in tourism product purchasing are constantly changing due to increased IT usage; however, 4 out of 5 of "Alpha's" managers do not share this view.

Only one manager actually recognized that, regardless of the fact that clients might not know what they want, when they eventually learn this, if "Alpha" provides them with exactly what they want, their level of satisfaction will grow along with the level of satisfaction and trust towards "Alpha" which is the agency's ultimate goal. In other words, his/her attitude is complemented, to some extent, by Fletcher et al., (1995) who stated that, by implementing eCRM, organizations will be able to provide low cost leadership, product differentiation and concentrate on niche markets but the importance of niche markets will differ depending on the context.

Table 3 offers a summary of the key points of the literature and current findings. 
Table 3. Summary of Literature and Study's Findings

\begin{tabular}{l}
\hline Literature \\
Buttle (2004) indicates that a strategic alternative \\
of e-CRM does not exist for enterprises; as such, \\
they should develop a relentless approach towards \\
creating customer centricity because, through this, \\
they will achieve current, future and lifetime \\
profitability by creating customers for life
\end{tabular}

Bonnemaizon, et al. (2007) state that whether or not people embrace the benefits of e-CRM depends on where they are positioned on the "stone age man" to "gadget boy" continuum

Davids (1999) claims that CRM implementation can face serious difficulties, or even outright failure, if it does not deliver profitable growth and it can even damage existing customer relationships

Buhalis (1999) states that customization, as added value, is of extreme importance due to the fact that the number of competitors is constantly increasing because of globalization, and at the same time customer's lifestyles and perceptions about risk involvement in tourism product purchasing are constantly changing due to increased IT usage

Fletcher et al. (1995) assert that by implementing e-CRM, organizations will be able to provide low cost leadership, product differentiation and concentrate on niche markets but the importance of niche markets will differ depending on the context

Buhalis (1999), Christou \& Kassianidis (2002); Faulkner et al. (2001) point out that tourism products can now be bought without almost any physical effort, and with no time pressure involved is the key point of e-CRM

\section{Findings}

While nowadays younger managers' are discussing an segmentation approach where clients, above 50 years old, would not even be targeted through an e-commerce campaign; and new generation clients, or those who would accept everything offered to them online, would not perceive a lack of face to face contact as a problem

"Old school" managers agree with Bonnemaizon et al. (2007) by claiming that face to face contact is a necessity in the tourism industry and that an agency branch can never be replaced

While nowadays, "Alpha's" managers' are claiming that e-commerce must be implemented at any cost, even if at the expense of existing client relationships

While nowadays, "Alpha" managers showed a significant lack of understanding, since all but one perceived that it is only a niche market which can easily be taken away by bigger foreign agencies, and that this option is only a waste of money

Only one manager of "Alpha" agency actually recognized that. He claims that regardless of the fact that clients might not know what they want now, when they eventually learn this, if "Alpha" provides them with exactly what they want, their level of satisfaction will grow along with the level of satisfaction and trust towards "Alpha" which is the agency's ultimate goal

"Alpha's" managers are claiming that the time saving factor is not the most important thing related to e-commerce implementation; in contrast, however, paying is an important time saving factor since e-commerce makes the process a lot simpler

\section{Discussion}

Respondent views tended to show coherency with the literature in most cases; however, regardless of the fact that many authors (e.g., Buhalis, 1999; Christou and Kassianidis, 2002; Faulkner et al., 2001) agree that tourism products can now be bought without almost any physical effort, and with no time pressure involved. "Alpha's" managers agree with their clients on this point since they stated that the time saving factor is not the most important thing related to e-commerce implementation; in contrast, however, paying is an important time saving factor since e-commerce makes the process a lot simpler; but still not safer since, according to Strauss et al. (2006) lack of secure online paying method is very important factor in e-business adoption.

Two out of five of (40\%), "Alpha's" managers perceived previous problems in contradiction with the views of Buttle (2004) who indicated 
that the strategic alternative of e-CRM does not exist for enterprises and, therefore, enterprises have to develop a relentless approach in heading towards customer centricity in order to achieve current, future and lifetime profitability and, as a consequence, customers for life.

Managers' of "Alpha" do not perceive CRM introduction in the same way as Buttle (2004), but are more in line with Bonnemaizon et al. (2007). The suggestion is that whether or not people embrace the benefits of e-CRM depends on where they are positioned on the "stone age man" to "gadget boy" continuum. "Old school" managers tend to claim that face to face contact is a necessity in the tourism industry and that an agency branch can never be replaced. This is in contrast to younger managers who elaborated an approach based on segmentation, where clients, above 50 years old, would not even be targeted with ecommerce, while new generation clients or those that will accept most things offered to them online would not perceive the lack of face to face contact as a problem.

Afterwards, when asked about profitability of eCRM implementation, "Alpha" management disagreed with the works of Davids (1999) since "Alpha" managers are claiming that ecommerce must be implemented at any cost, even at the risk of damaging existing client relationships, due to the fact that if "Alpha" wants to keep a leadership role, they have to follow through; if they do not offer e-tourism to clients, someone else will.

The previous misconception about relationships that "Alpha's" managers had, naturally emerged when they were asked to reflect upon online customization of the arrangements, as a sign of trust for the agency, since all but one perceived that it is only a niche market which can easily be taken away by bigger foreign agencies, and that this option is only a waste of money, since profitability will not grow proportionally with the satisfaction of the clients.

Buhalis (1999) does not share the same opinion since he stated that online customization, as added value, is of extreme importance due to the fact that the number of competitors is constantly increasing because of globalization, and at the same time customer's lifestyles and perceptions about risk involvement in tourism product purchasing are constantly changing due to increased IT usage. Their attitudes complement, to some extent, those of Fletcher et al. (1995) who stated that, by implementing e-CRM, organizations will be able to provide low cost leadership, product differentiation and concentration on niche markets. This is in alignment with the agency view that e-CRM implementation would enable "Alpha" to target niche markets; however, the importance of niche market targeting is not significant for the majority of "Alpha's" managers.

In summary, "Alpha's" managers showed significant levels of misunderstanding of each other and, although "Alpha" operates satisfactorily at present, and the level of client satisfaction is quite high, there is scope to positively influence both the level of satisfaction and profitability which would enable clients and managers of "Alpha" to understand each other much better. In other words, "Alpha's" management should consider what Milikić et al., (2008) suggest which is to develop comparative CRM, which refers to adapted CRM practices within regional and national contexts, since cultural and institutional differences between countries and regions require CRM policies and practices to be distinctive for every region. That is, CRM is the only way to create strategic advantage for the company, and at the same time give clients exactly what they want, as suggested by Hermans and Mount (2010). Additionally it could be done through locally negotiated loyalty benefits and rewards, and by elite interviewee number 1 ; this could be achieved through measuring guests' sensitivity to intangible rewards, the creation of private brand spaces, integrating and customizing brand communication into the pre-departure and postdeparture service process, actual guest network expansion through existing guests, both on and off-line and through social media.

Again, a good example of developing comparative CRM, which refers to adapted CRM practices within regional and national contexts is showed in research of Pilav-Velic 
(2010); a research that illustrates a five step approach, developed for the Bosnian market, which is very similar to Serbian, and it could easily be implemented by managers in tourism sector as well as in other sectors in the Serbian market.

\section{Conclusions}

The purpose of this research was to shed a light on e-CRM implementation in Serbian tourism industry, since to date little has been written about e-CRM implementation in developing economies such as Serbian, and even less in the tourism sector, which is why companies that do try to introduce CRM, and especially e-CRM, do so based on US models; which is why this research is creating comparative e-CRM practice for Serbian model of e-CRM in tourism.

Findings suggest that time saving factor of online product purchase is not a key factor with Serbian customers, but that paying is; since online credit card purchases are much simpler and less time-consuming than actually paying cash. Research also showed differences in opinions of managers who studied in the communist era, and of those who studied recently, since the beliefs of "older" generation managers are that nothing can replace the regular tourist agency, while those "younger" believe in the e-CRM revolution. However, they all agreed on one thing, which is that online arrangement customization will eventually be profitable, but will only attract a niche market of customers, which is something that literature does not agree on.

The investigation also adds to our knowledge that the role of technology in respect to building knowledge between the institution and its customer base through e-CRM currently is willingly bypassed by management. It could be postulated that main reason for this is managers' lack of understanding of e-CRM, or may be the uncertainty that e-commerce is triggering as to how to employ new marketing initiatives or tailor e-CRM to the Serbian tourism sector.

Managers' reluctance to incorporate e-CRM initiatives into their strategies should be perceived with caution, since it could be argued that managers try to differentiate from western academic rhetoric. This suggests that if their institutions do invest in e-CRM they may be able to form effective relationships with their ecustomer clientele; hence the enhancement of cross-selling opportunities and positive word of mouth could contribute to the institution's profitability.

However, such theoretical reasoning substantially lacks any acceptance of the nature and level of investment required for eCRM. More specifically it is vague about whether investing in e-CRM will bring realistic outcomes to the organization; and it is so because instance of financial investment is dominating the managers' discourse. This investigation currently suggests that the whole notion of CRM and e-CRM is perceived as a western pedantic conceptual construct that is a long way from the Serbian practitioners' strategies.

However, study presents some unavoidable limitations. One of the main problems casestudy research faces is case selection, since researchers have faulty assumptions that cases should be representative of some population like data are in large-scale hypothesis research. But the purpose of the research is to build a theoretical background, not to test it on a random or stratified sample (Eisenhardt and Graebner, 2007). Therefore, a limitation factor for this research is that only "Alpha" agency managers were included in the research and, as a consequence, the results of this research will be hard to generalize, but still useful since "Alpha" agency is perceived as pioneer on Serbian market; an agency that other agencies follow.

Also, Stall-Meadows and Hyle, (2010) assert that case studies findings could lack generalizability. However, Remenyi et al. (1998:180) state, that value of case studies relies on "in-depth evidence that is evaluated on the basis of analytical generalizations" where researchers' purpose in this project was to reassure authenticity and the proper representation of the phenomenon being investigated (Remenyi et al., 1998). Therefore, the researchers are interpreting the extent to which this study's findings apply to other 
situations up to the people in those situations. Merriam (1998) refers to this as reader or user generalisability.

A quality of case study research is perceived as generally low, but that criticism is empirically unsupported (Pedrosa et al., 2012), while another problem that case-study research faces is suspicion that the data is biased. This challenge, however, may be mitigated with data collection approaches that are limiting bias and using numerous and highly knowledgeable informants who are viewing the phenomena from diverse perspectives (Eisenhardt and Graebner, 2007). For this reason, five interviews were conducted, with managers of "Alpha" agency, starting with the general director, down to the level of regional managers.

Future research should include customers' point of views in order to provide a better picture of the market. Particularly, a future study should explore CRM in ex-communist countries in a comparative manner, due to the fact that people in those countries tend to feel high levels of collectivism, power distance, and uncertainty avoidance, as stated by Hofstede (2001), which is why their perceptions of CRM are quite different to perceptions of people from Western countries.

The biggest benefit that this research may provide, however, is the suggestion to create comparative CRM practices in the tourism industry in Serbia, something that has not existed to date. As such, in the future, this may make Serbian tourism companies regionally competitive, since customer relationship marketing is quickly becoming a key differentiation factor among many tourism market operators.

Regardless of everything previously mentioned, the fact is that Eastern European companies should take a step-by-step approach in implementing e-business methods. Such a cautious strategy is expected to take into account a company's identity and image with customers as well as an assessment of possible impacts and results. Although it is acknowledged that e-commerce offers the scope for further cost savings and for deepening relationships with regular customers, some companies in the travel and tourism industry are still reluctant to proceed faster, arguing that their next steps will depend on the market and industry circumstances (Taga et al., 2011). It is so because the market is not mature enough yet, and there is an insufficient number of experienced Internet users. This is particularly evidenced in the approach of some companies operating in less mature, small markets who do not feel threatened by increasing competition and see CRM strategies as "peripheral" to their activities (Taga et al., 2011), and Serbia is that kind of a market.

\section{References}

Ab Hamid, N.R. (2005). E-CRM: Are we there yet? Journal of American Academy of Business 6, 51-57.

Adebanjo, D. (2003). Classifying and selecting e-CRM applications: An analysis-based proposal. Management Decision, 41 (6), 570-577.

Adzic, S. \& Jevtic, M. (2010). New macroeconomic framework for business: Case study for Serbia. Journal of International Business and Economics, 10 (1), 41-67.

Amila, P. (2010). (E)CRM in Companies in the Bosnian Market. Zbornik Radova, 30, 295-309.

Al-Momani, K. \& Noor, N. A. M. (2009). Eservice quality, ease of use, usability and enjoyment as antecedents of $\mathrm{e}$ CRM performance: An empirical investigation in Jordan mobile phone services. The Asian Journal of Technology Management, 2 (2), 50-64.

Bennett, M. \& Chi-Wen, K. L. (2005).The impact of the internet on travel agencies in Taiwan. Tourism and Hospitality Research, 6(1), 8-23.

Berg, B. L. (2004). Qualitative research methods for the social sciences. Boston: Pearson.

Blery, E. K. \& Michalakopoulos, M. G. (2006). An e-CRM application in the telecommunications sector: A case study from Greece. EuroMed Journal of Business, 1 (2), 5-14.

Bonnemaizon, A., Cova, B. \& Louyot, M-C. (2007). Relationship marketing in 2015: 
A Delphi approach. European Management Journal, 25(1), 50-59.

Bonoma, T. V. (1985). Case research in marketing: Opportunities, problems and a process. Journal of Marketing Research, 22(2), 199-208.

Buhalis, D. (1999). Information technology as a strategic tool for sustainable tourism development. The Courier, 175 (1) 5557.

Buttle, F. (2004). Customer relationship management: Concepts and tools. Sydney: Elsevier.

Carson, D., Gilmore, A., Perry C. \& Gronhaug, K. (2005). Qualitative marketing research. London: Sage Publications.

Christou, E. \& Kassianidis, P. (2003). Consumer's perceptions and adoption of online buying for travel products. Journal of Travel and Tourism Marketing, 12 (4), 93-107.

Davids, M. (1999). How to avoid the 10 biggest mistakes in CRM. The Journal of Business Strategy, 20 (6), 22-26.

Denzin, N. \& Lincoln, Y. (2008). Strategies of qualitative inquiry. Beverly Hills, CA: Sage Publications.

Desal, D. \& Sahu, S. (2008). CRM Change management in an emerging country context: An exploratory study in India. Global Journal of Flexible Systems Management, 9 (2/3), 41-53.

DiGregorio, D., Kassicieh, S. \& DeGouveaNeto, R. (2005). Drivers of e-business activity in developed and emerging markets. Engineering Management: IEEE Transactions, 52 (2), 155-166.

Dyche, J. (2001). The CRM handbook: $A$ business guide to customer relationship management. Reading, MA: AddisonWesley.

Dugan, K. \& Lang, J. (2010). Six drivers for high-user satisfaction of tourism websites: Performance auditing of Maine, Massachusetts, and New York's direct marketing strategies. Advances in Culture, Tourism and Hospitality Research, 4, 27-45.

Eisenhardt, K. \& Graebner, M. (2007). Theory building from cases: Opportunities and challenges. Academy of Management Journal, 50 (1), 25-32.
Faulkner, B., Moscardo, G. \& Laws, E. (2001). Tourism in the $21^{\text {st }}$ Century. London: British Library Cataloguing.

Feinberg, R. \& Kadam, R. (2002). e-CRM web service attributes as determinants of satisfaction with retail websites. Journal of Service Industry Management, 13 (5), 432-451.

Fink, D. \& Disterer, G. (2006). International case studies: To what extent is ICT infused into the operation of SMEs. Journal of Enterprise Information Management, 19 (6), 608-624.

Finnegan, D. J. \& Currie, W. L. (2010). A multilayered approach to CRM implementation: An integration perspective. European Management Journal, 28 (2), 153-167.

Fletcher, J., Parlett, G. \& Cooper, C. (1995). The Impact of Tourism on the Old Town of Edinburgh, Tourism Management, 16 (5), 335-360.

Flyvbjerg, B. (2006). Five misunderstandings about case-study research. Qualitative Inquire, 12 (2), 219-245.

Fruhling, A. \& Keng, S. (2007). Assessing organizational innovation capability and its effect on e-commerce initiatives. Journal of Computer Innovation Systems, 48 (1), 133-145.

Fux, M., Mathieu, D. S. \& Go, F. (2007). Integrated electronic customer relationship management (CRM) for Alpine tourist destinations: Drivers and an adoption framework. Information and Communication Technologies in Tourism, 9, 413-424.

Gerring, J. (2009). Case study research: Principles and practices. Cambridge: Cambridge University Press.

Gospic, N. \& Bogojevic, D. (2010). Urban and rural telecommunications development: Identification of a digital/broadband gap in Serbia. IEEE Global Communications Newsletter, July 2010.

Grönroos, C. (2007). Service management and marketing: Customer management in service competition. New York: Wiley.

Gummesson, E. (1987).The new marketingdeveloping long-term interactive relationships. Long Range Planning, 20 (4), 10-20. 
Hale, M. (2006). Share your fountain of travel knowledge, Travel Trade Gazette. April, 21, p.15.

Hammarkvist, K., Hakansson, H. \& Mattsson, L. (1982). Marknadsforing for konkurrenskraft [Marketing for Competitiveness]. Kristianstad: Liber.

Harris, R. \& Davison, R. (1999). Anxiety and involvement: Cultural dimensions of attitudes towards computers in developing countries. Journal of Global Information Management, 7 (1), 26-38.

Harker, J. \& Egan, J. (2006). The past, present and future of relationship marketing. Journal of Marketing Management, 22 (12), 215-242.

Harrigan, P., Ramsey, E. \& Ibbotson, P. (2011). Critical factors underpinning the e-CRM activities of SMEs. Journal of Marketing Management, 27 (5), 503-529.

Heng-Hsiang, H. \& Chou-Kang, C. (2006). Exploring customer satisfaction, trust and destination loyalty in tourism. Journal of American Academy of Business, 10 (1), 156-159.

Hermans, O. \& Mount, D. (2010). Customer relationship management in hospitality: Adding a relationship dimension to a relational service. Journal of Hospitality and Tourism Research, 30 (2), 191206.

Hofstede, G. (2001). Difference and danger: Cultural profiles of nations and limits to tolerance. London: Blackwell.

Holden, L. (2001). International human resource management. Upper Saddle River, NJ: Prentice Hall.

Howe, K. (2011). Living in a Transactional World. Marketing Week, 34(13), p. 51

Hu, C., Han, Y., Jang S. \& Bai, B. (2005). ERelational characteristics on hospitality and tourism program web sites. Journal of Hospitality and Tourism Research, 29 (4), 508-522.

Hultman, C. \& Shaw, E. (2003).The interface between transactional and relational orientation in small service firm's marketing behaviour: A study of Scottish and Swedish small firms in the service sector. Journal of Marketing Theory and Practice, 11 (1), 36-51.

James, W., Torres-Baumgarten, G., Petkovic, G., \& Havrylenko, T. (2009). A psychographic profile of users of internet-related technologies in Serbia and the Ukraine. Journal of East-West Business, 15 (2), 119-140.

Jayachandran, S., Sharma, S., Kaufman, P. \& Raman, P. (2005). The role of relational information processes and technology use in customer relationship management. Journal of Marketing, 69 (4), 177-192.

Kapoulas, A., Murphy, W. \& Ellis, N. (2002). Say hello, wave goodbye: Missed opportunities for electronic relationship marketing with the financial services sector. International Journal of Bank Marketing, 20 (7), 302-313.

Karanasios, S. \& Burgess, S. (2008). Tourism and internet adoption: A developing world perspective. International Journal of Tourism Research, 10 (2), 169-182.

Kennedy, A. (2006). Electronic customer relationship management (eCRM): Opportunities and challenges in a digital world. Irish Marketing Review 18 (1/2), 58-68.

Khosrow-Pour, M. (2006). The impact of ecommerce technology on the air travel industry. Hershey, PA: IGI Publishing.

Kothari, T., Hu, C., \& Roehl, W. S. (2007). Adopting e-procurement technology in a chain hotel: An exploratory case study. International Journal of Hospitality Management, 26 (4), 886898.

Kotorov, R. (2002). Ubiquitous organisational design for e-CRM. Business Process Management Journal, 8(3), 218-232.

Lee-Kelley, L., Gilbert, D. \& Mannicom, R. (2003). How e-CRM can enhance customer loyalty. Marketing Intelligence and Planning 21 (4/5), 239-248.

Letaifa, S. B. \& Perrien, J. (2007). The impact of $\mathrm{E}$ - CRM on organizational and individual behaviour: The effect of the remuneration and reward system, International Journal of E-Business Research, 3 (2), 13-23.

Mamaghani, F. (2009). Impact of e-commerce on travel and tourism: An historical analysis, International Journal of Management, 26 (3), 365-375.

Matopoulos, A., Vlachopoulou, M. \& Manthou, V. (2007). Exploring the impact of e- 
Business adoption on logistics processes: Empirical evidence from the food industry. International Journal of Logistics: Research and Applications, 10 (2), 109-122.

Merriam, S. B. (1998). Qualitative research and case study applications in education. San Francisco: Jossey Bass.

Mikkelsen, B. (1995). Methods for development work and research: $A$ guide for practitioners. London: Sage Publications.

Milikić, B., Janićijević, N. \& Petković, M. (2008). HRM in transition economies: The case of Serbia. South East European Journal of Economics and Business, 3 (2), 75-88.

Moore, N., \& Stokes, P. (2012). Elite interviewing and the role of sector context: an organizational case from the football industry. Qualitative Market Research: An International Journal, 15(4), 438-464.

Morphitou, R. (2009). A Preliminary investigation of the understanding and implementation of CRM Systems in Cyprus. Paper presented at the $8^{\text {th }}$ International Congress Marketing Trends, Paris, 16 -17 January 2009.

Osti, L., Turner, L. \& King, B. (2009). Cultural differences in travel guide-book information search. Journal of Vacation Marketing, 15 (1), 63-78.

Pan, S. L. \& Lee J. (2003). Using e-CRM for a unified view of the customer. Communications of the ACM, 46 (4), 95-99.

Pedrosa, A., Näslund, D., \& Jasmand, C. (2012). Logistics case study based research: towards higher quality. International Journal of Physical Distribution \& Logistics Management, 42(3), 275-295.

Peppard, J. (2000). Customer relationship management (CRM) in financial services. European Management Journal, 18 (3), 312-327.

Peppers, D. \& Rogers, M. (2002). Customer relationship management in Asia - a cross-culture case study based on Aetna Universal Insurance. Global Journal of Flexible System Management, 27 (1), 39-40.
Pilav-Velic, A. (2010). (E)CRM in companies in the Bosnian market. Sarajevo Business and Economics Review, 30, 295-309 (in Croatian).

Priporas, C. V. \& Poimenidis, I. (2008). Services managers' awareness of crisis management: Attitudes and preparation. Innovative Marketing, 4 (3), 37-45.

Priporas, C. V. \& Vangelinos, G. (2008). Crisis management in pharmaceuticals. Evidence from Greece. International Journal of Pharmaceutical and Health Care Marketing, 2 (2), 88 -102.

Racherla, P. \& Hu, C. (2008). eCRM system adoption by hospitality organizations: A technology-organization-environment (TOE) framework. Journal of Hospitality Marketing and Management, 17 (1), 30-58.

Reinartz, W., Kraft, M. \& Hoyer, W. (2004). The customer relationship management process: Its measurement and impact on performance. Journal of Marketing Research, 41 (3), 293-305.

Remenyi, D., Williams, B., Money, A. \& Swartz, E. (1998). Doing research in the business and management: An introduction to process and method. London: Sage Publications.

Republican Statistical Office of the Republic of Serbia (2009). Usage of informationcommunicational technologies in the Republic of Serbia. Available at http://webrzs.stat.gov.rs/axd/dokumenti /ict/2010/ICT2010s.zip (accessed 7 August 2010).

Samanta, I. (2009). The impact of e-customer relationship marketing in hotel industry, International Journal of Knowledge and Learning, 5 (3-4), 333-346.

Sampaio, P. \& Yong, H. (2006). Unbundling and delivering CRM applications as eservices: A case study in customer segmentation. International Journal of Services Technology and Management, 7 (3), 297-319.

Sigala, M. (2011). eCRM 2.0 applications and trends: The use and perceptions of Greek tourism firms of social networks and intelligence. Computers in Human Behavior, 27 (2), 655-661. 
Sigala, M. (2006). Culture: The software of CRM. Journal of Marketing Communications, 12 (3), 203-223.

Sophonthummapharn, K. (2009). The adoption of techno-relationship innovations. A framework for electronic customer relationship management. Marketing Intelligence and Planning, 27 (3), 380412.

Stall-Meadows, C. \& Hyle, A. (2010). Procedural methodology for a grounded meta-analysis of qualitative case studies. International Journal of Consumer Studies, 34 (4), 412-418.

Strauss, J., El-Ansary, A. \& Frost, R. (2006). EMarketing. Upper Saddle River, NJ: Pearson/Prentice-Hall.

Taga, H., Gaspari, A. \& Vukaj, H. (2011). Implementation of customer relationship management in Albania travel industry: Its overall impact on performance. Journal of Marketing and Management, 2(1), 51-60.

Tapan, P. (2006). Contemporary marketing: The changing face of marketing in $21^{\text {st }}$ century Hyderabad, India: ICFAI University Press.

Teng, K. L. L., Soo, G. O. \& Poon, W. C. (2007). The use of customer relationship management (CRM) by manufacturing firms in different industries: A Malaysian survey. International Journal of Management, 24 (2), 386-397.

Thomas, D. (2002). CRM is key to winning customers. Computer Weekly, 14 (7)

Xiang, L. \& Petrick, J. (2008). Tourism marketing in an era of paradigm shift. Journal of Travel Research, 46 (3), 235-244.

Yin, R. K. (2008). Case study research: Design and methods. Thousand Oaks, CA: Sage Publications.

Zupan, N. \& Kaše R. (2005). Strategic human resource management in European transition economies: Building a conceptual model on the case of Slovenia. International Journal of Human Resource Management, 16 (6), 882-906. 